\title{
Food insecurity and the risk of depression in people living with HIV/AIDS: a systematic review and meta-analysis
}

\author{
Getinet Ayano ${ }^{1,2^{*}}$, Light Tsegay ${ }^{3}$ and Melat Solomon ${ }^{1}$
}

\begin{abstract}
Background: The link between food insecurity and depression in people living with HIV/AIDS (PLWHA) has been explored in numerous studies; however, the existing evidence is inconclusive due to inconsistent results. Therefore, the objective of this systematic review and meta-analysis is to examine the relationship between food insecurity and depression in PLWHA.

Methods: We systematically searched PubMed, EMBASE, and Scopus to identify relevant studies. A random-effect model was used for conducting the meta-analysis. We assessed the risk of publication bias by funnel plot and Egger's regression asymmetry test.

Results: In this review, seven studies were included in the final analysis. Our meta-analysis revealed that food insecurity significantly increased the risk of depression in PLWHA [RR $2.28(95 \% \mathrm{Cl} 1.56-3.32)]$. This association remained significant after adjusting for the confounding effects of drug use [RR 1.63 (95\% Cl 1.27-2.10)], social support [RR 2.21 (95\% Cl 1.18-4.16)] as well as ART drugs [RR 1.96 (95\% Cl 1.17-3.28)]. Our subgroup and sensitivity confirmed the robustness of the main analysis.

Conclusion: This systematic review and meta-analysis suggest a significant association between food insecurity and increased risk of depression PLWHA. Therefore, early screening and management of food insecurity in PLWHA seem to be necessary.
\end{abstract}

Keywords: Food insecurity, Depression, HIV, AIDS, Systematic review, Meta-analysis

\section{Introduction}

According to the U.S. Department of Agriculture, food insecurity refers to "a lack of consistent access to food for an active, healthy life" [1]. Food insecurity is a considerable problem in both developed and developing countries with greater prevalence in developing than developed countries [2-4]. For example, previous studies showed that in 2016 about 15.6 million households in American

\footnotetext{
*Correspondence: babiget2015@gmail.com

${ }^{1}$ Research and Training Department, Amanuel Mental Specialized Hospital Addis Ababa, PO BOX 1971, Addis Ababa, Ethiopia

Full list of author information is available at the end of the article
}

[5] and 52\% of households in South Africans in 2005 were found to be food insecure households [6].

Epidemiologic evidence also showed that the reported prevalence of food insecurity is remarkably high in people living with HIV/AIDS (PLWHA) and is associated with poor HIV health outcomes [7, 8]. For instance, A 2009 study conducted in India found that $56 \%$ of PLWHA were food insecure at the time of enrollment to the study [9]. In another study conducted in Russia, the prevalence of food insecurity among PLWHA was $46 \%$ [10].

A substantial body of evidence has linked food insecurity in PLWHA to an increased risk of depression $[11,12]$. For example, a 2011 study conducted in Uganda found that food-insecure PLWHA who were food insecure

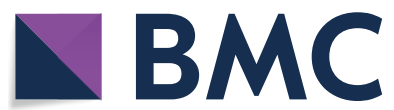

(c) The Author(s) 2020. This article is licensed under a Creative Commons Attribution 4.0 International License, which permits use, sharing, adaptation, distribution and reproduction in any medium or format, as long as you give appropriate credit to the original author(s) and the source, provide a link to the Creative Commons licence, and indicate if changes were made. The images or other third party material in this article are included in the article's Creative Commons licence, unless indicated otherwise in a credit line to the material. If material is not included in the article's Creative Commons licence and your intended use is not permitted by statutory regulation or exceeds the permitted use, you will need to obtain permission directly from the copyright holder. To view a copy of this licence, visit http://creativeco mmons.org/licenses/by/4.0/. The Creative Commons Public Domain Dedication waiver (http://creativecommons.org/publicdomain/ zero/1.0/) applies to the data made available in this article, unless otherwise stated in a credit line to the data. 
were found to be 2.83 times more likely to develop major depressive disorders as compared to those PLWHA who were food secure [13]. In a more recent study conducted in the USA, those PLWHA who were in a very low food insecure stage were found to be 4.19 times more likely to develop depression as compared to food secure PLWHA [11].

Although the above epidemiologic studies found a greater risk of depression in PLWHA who were food insecure, these results are not constant all over the available studies; there are also articles that reported no significant risk of depression in PLWHA [14]. Thus, the objective of this systematic review and meta-analysis is to examine the relationship between food insecurity and depression in PLWHA in order to conclude the association and formulate implications for future epidemiologic research and clinical practice.

\section{Methods}

\section{Research method and designs}

We conduct this systematic review and meta-analysis in accordance with the preferred reporting items for systematic review and meta-analysis guidelines (PRISMA) [15]. We utilized a pre-defined protocol for search strategy, data extraction, study selection, as well as analysis.

\section{Data source and searches}

Three authoritative electronic databases (EMBASE, PubMed, and Scopus) were systematically searched for pertinent studies. We searched without restriction on the date of publication. The systematic literature search was conducted in May 2019. The search terms and keywords included (Food insecurity OR food insufficiency) AND (HIV OR Human immune deficiency Virus OR AIDS OR Acquired immune deficiency syndrome) AND (depression OR depressive symptom OR depressive disorder). We also manually searched to identify additional relevant studies.

\section{Inclusion and exclusion criteria}

Articles satisfying the following criteria were included in this study: First, all observational study (case-control, cross-sectional or cohort stud). Second, the exposure of interest was food insecurity. Third, the outcome was depression. Fourth, the study population was PLWHA. Fifth, studies that reported relative risks (RR) or odds ratio, estimates with the respective $95 \%$ confidence intervals (CIs), or studies that reported data to calculate these. In this review, we excluded editorials, comments, case reports, reviews, letters, abstracts presentations, as well as studies published in a non-English language.

\section{Data extraction}

Two reviewers (MS and LT), in an independent manner, used a predesigned standard form to extract the data, which included the first author's name, publication year, the study design, country, confounders adjusted for, risk estimate (OR/RR) and their 95\% CI as suggested by PRISMA guidelines [16]. We resolved disagreements were by consensus.

\section{Study quality}

The Newcastle-Ottawa quality evaluation scale (NOS) [17] was used to assess the quality of the included studies. The NOS scale evaluates the quality of the included studies in three areas such as comparability between the groups, recruitment of the participants, and assessment of exposure and outcome. For the cross-sectional studies, we used a modified version of NOS [18]. In fact, studies were not excluded based on the quality assessment score alone.

\section{Data synthesis and analysis}

Comprehensive Meta-Analysis (CMA) software version3 was employed to conduct the meta-analysis [19]. In those studies that reported multiple estimates, we used the estimate with the most extensive adjustment and with the highest degree of food insecurity. To account for the heterogeneity across the studies, the random effect model was used to combine the effect estimate from included studies [20]. Q and the $\mathrm{I}^{2}$ statistics were used to assess heterogeneity [20]. The $\mathrm{I}^{2}$ statistics values such as 25,50 , and $75 \%$ represented low, moderate, and high heterogeneity respectively [21]. All the reported probabilities were two-sided. To assess the key studies that exerted a considerable impact on the heterogeneity we carried out a leave-one-out sensitivity analysis [22]. We also performed subgroup and sensitivity analysis to compare the risk between the groups as well as determining the potential source of heterogeneity between the studies. We evaluated a publication by funnel plot and Egger's regression test [23].

\section{Results \\ Study selection}

The search strategy resulted in 278 studies. Six additional relevant references were identified through our manual search. Our review of these studies by title, duplicate, and abstract resulted in the exclusion of 264 studies, as they did not meet the predefined inclusion criteria. Our further screening of a full text of the remaining 20 articles resulted in the exclusion of 
Identifications

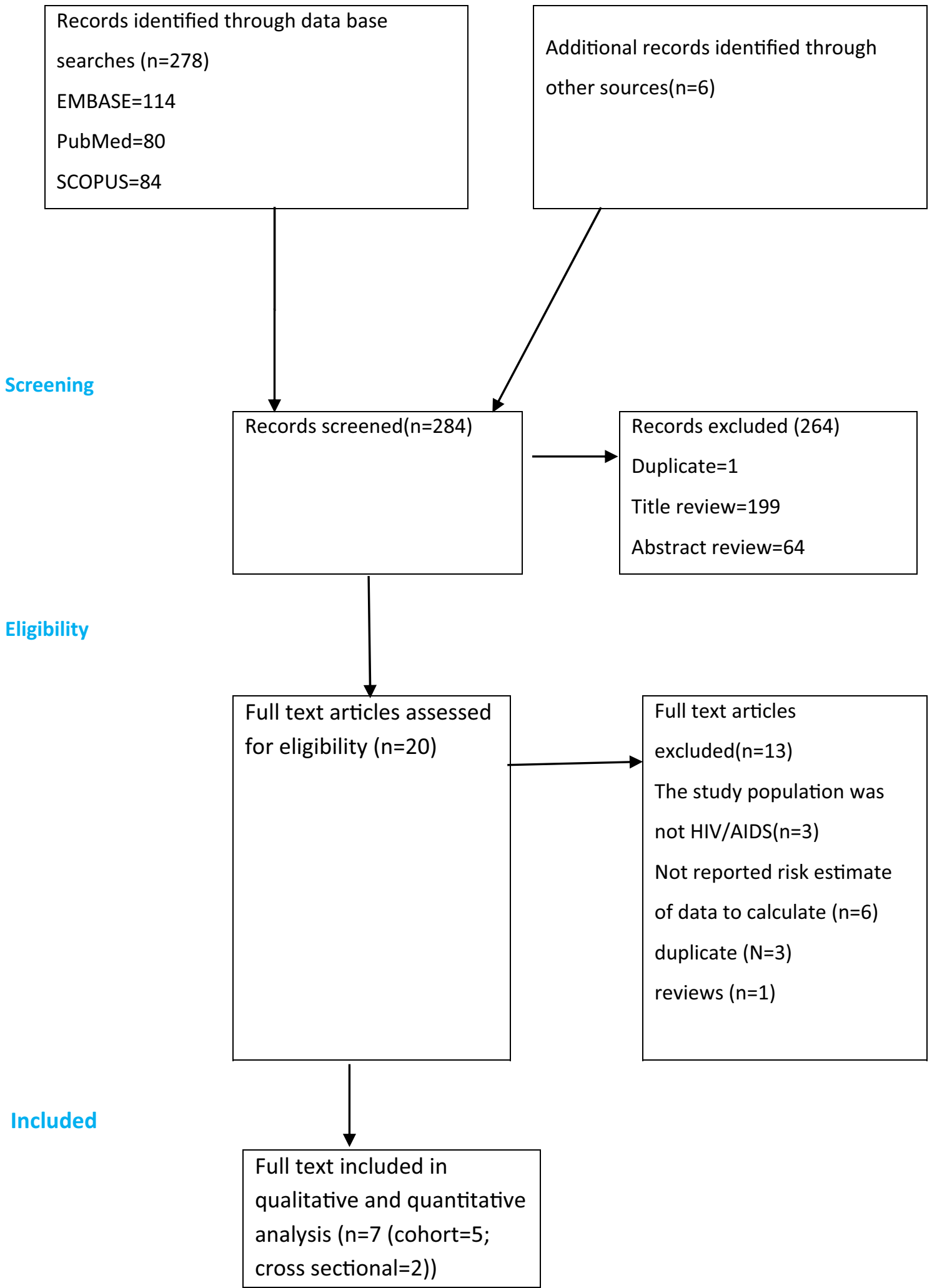

Fig. 1 PRISMA flowchart of review search 
further 13 studies. Therefore, seven studies were found eligible for the final analysis (Fig. 1).

\section{Characteristics of included studies}

Table 1 shows the characteristics of the included studies. The included studies were published between December 2011 [24] and June 2018 [11]. Most of the included studies (5 studies) were conducted in the USA [11, 14, 25-27], one study conducted in Uganda [24], and one in Ethiopia [28]. Five were cohort studies [11, 14, 25-27] and two were cross-sectional studies [24, 28]. Two studies adjusted for the possible confounding effects of drug use [11, 14], two adjusted for ART drug use [11, 24], and two adjusted for social support [14, 24].

Regarding the tools used to assess depression, from the total, four studies used the Center for Epidemiologic Studies Depression Scale (CESD) [11, 25-28], one study used Mini-International Neuropsychiatric Interview (MINI) [24], one study used Beck depression inventory (BDI) [14] and one study used Burnam depression screen (a short form of CESD) [14]. Of these four instruments used to assess depression, three of them are screening [29-31] and one is a diagnostic instrument [32]. Regarding the instruments used to assess food insecurity, two studies used the Household Food Insecurity Access Scale (HFIAS) [27, 28], two studies used the Household Food Insecurity Survey Module (HFSSM) [11, 26], one study used Radimer/corner questionnaire of hunger and food insecurity [14], one study used Core Food Insecurity Module [25], and one study used self-reported food insecurity by participants [13].

\section{The quality of the included studies}

In this review, we used NOS, a 9-point scoring system to evaluate the study quality. Accordingly, all the included studies were good quality studies (the NOS score for the included studies ranges between eight and nine from the total 9 points) (see Additional file 1: Table S1).

\section{Food insecurity and risk of depression in PLWHA}

Figure 2 shows the forest plot indicating the relative risk and $95 \% \mathrm{CI}$ of each study as well as the overall pooled relative risk. To account for the observed heterogeneity between the included studies $\left(I^{2}=84.88 \% ; \mathrm{Q}=39.69\right.$; $\mathrm{df}=6 ; \mathrm{P}<0.0001$ ), we employed a random effect model. The meta-analysis of seven studies showed that the risk of developing depression was significantly higher in those PLWHA who were food insecure as compared to those who were food secure [RR 2.28 (95\% CI 1.56-3.32)].

\section{Subgroups analyses by study design}

In our subgroup analysis by the study design, the risk of developing depression based on cohort studies was 2.06
(95\% CI 1.36-3.12)), whereas based on cross-sectional studies was 3.24 (95\% CI 1.85-5.68). The heterogeneity was significant for cohort studies $\left(I^{2}=87.62 \% ; \mathrm{Q}=42.30\right.$; $\mathrm{df}=4 ; \mathrm{p}<0.0001)$, but not for cross-sectional studies $\left(I^{2}=0.00 \% ; \mathrm{Q}=0.23 ; \mathrm{df}=1 ; \mathrm{p}=0.630\right)$ (see Fig. 3 ).

\section{Subgroup analyses by the level of food insecurity}

In our stratified analysis by the level of food insecurity, the risk of depression was 1.83 (95\% CI 1.09-3.07)), 1.95 (95\% CI 0.85-4.52)), 2.59 (95\% CI 1.03-6.48)) respectively for mild, moderate and severe food insecurity. The observed differences in risk estimates between the groups were not statistically significant $(\mathrm{P}=0.813)$ (see Table 2 ).

\section{Publication bias}

The funnel plot and Egger's regression tests $(B=2.60$, $\mathrm{SE}=0.96, \mathrm{P}=0.042$ ) provided evidence of substantial publication bias for the association between food insecurity and the risk of depression in PLWHA (Fig. 4).

\section{Sensitivity analysis}

To identify the possible effects of drug use, we conducted stratified analysis by restricting the analysis to the studies that adjusted for the potential confounding effects of drug use. In this analysis, an increased risk of depression was observed in PLWHA who were food insecure in studies that accounted for the effects of drug use [RR 1.63 (95\% CI 1.27-2.10)] as it was in the studies with no adjustment [RR 2.71 (95\% CI 1.46-5.00)]. In this analysis, the observed difference in risk estimates of depression (RR) between the groups was not significant $(P=0.134)$. The reported heterogeneity across the studies was also not significant in studies that adjusted for the confounding effects of drug use $\left(I^{2}=0.00 \% ; \mathrm{Q}=0.034 ; \mathrm{df}=1\right.$; $\mathrm{p}=0.850$ ) but it was significant in those that did not adjust for the effects of drug use $\left(\mathrm{I}^{2}=89.83 \%\right.$; $\mathrm{Q}=39.30$, $\mathrm{df}=4, \mathrm{P}<0.001)($ see Table 2).

We further conducted the sensitivity analysis by restricting the analysis to studies that adjustment for confounding effects of lack of social support. We found an increased risk of depression in PLWHA who were food insecure in studies that accounted for the effect of social support [RR 2.21 (95\% CI 1.18-4.16)] as well as in studies that did not account for confounding effects of social support [RR 2.32 (95\% CI 1.48-3.63)]. This analysis resulted in no significant heterogeneity between studies that adjusted for social support $\left(I^{2}=18.02 \% ; \mathrm{Q}=1.22\right.$; $\mathrm{df}=1 ; \mathrm{p}=0.269)$ but it was significant in those that did not adjust for social support $\left(\mathrm{I}^{2}=89.07 \% ; \mathrm{Q}=36.61\right.$, $\mathrm{df}=4, \mathrm{P}<0.001)($ see Table 2$)$.

Finally, we performed the analysis by restricting the analysis to studies that accounted for potential confounding effects of ART drug treatment because evidence 


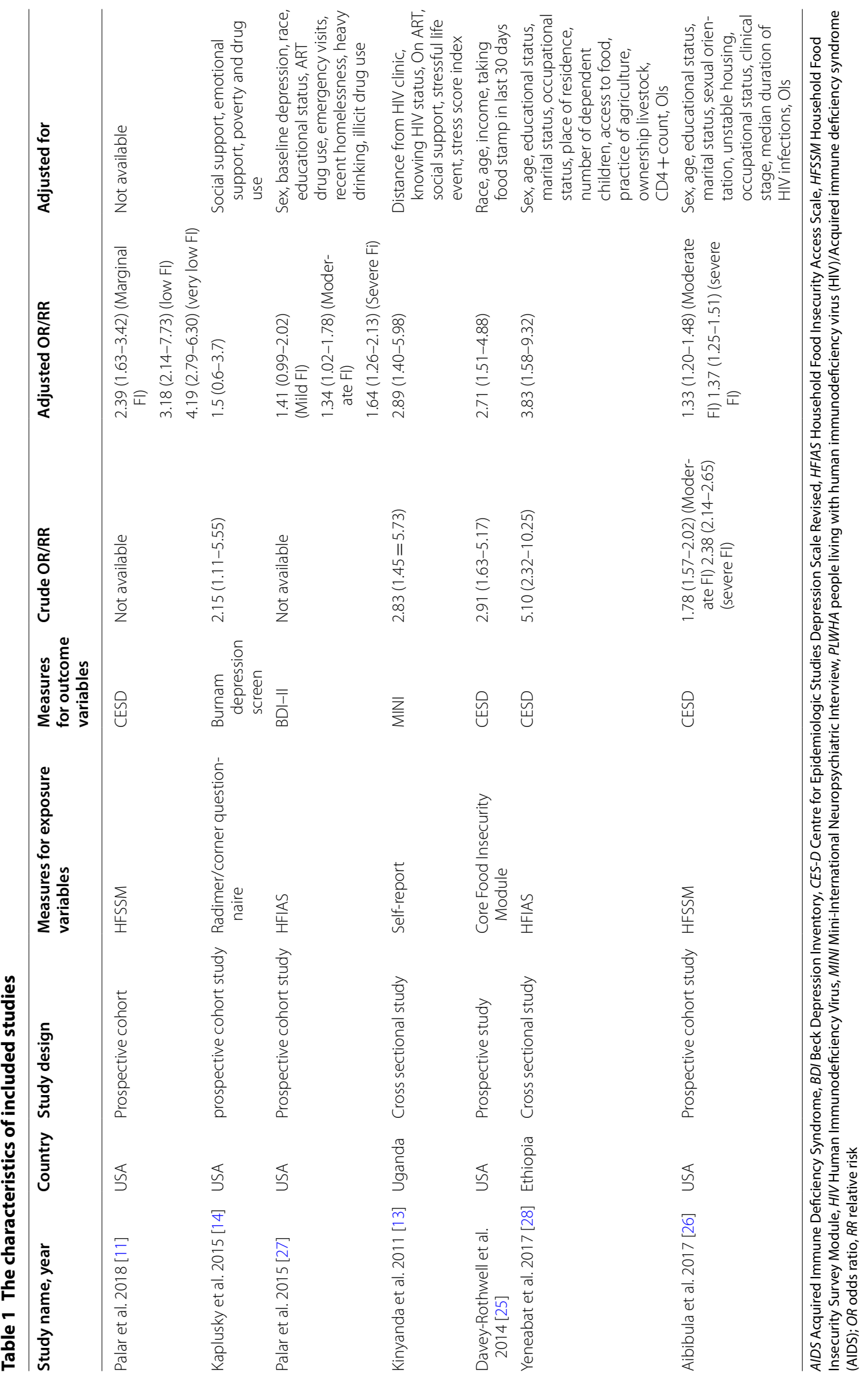




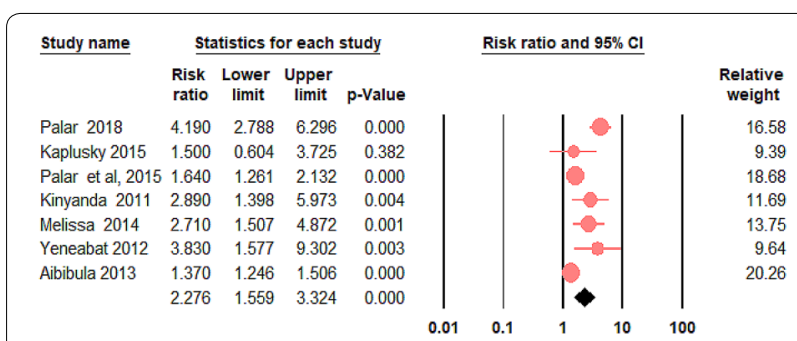

Fig. 2 The forest plot of the association between food insecurity and depression in PLWHA suggests that antiretroviral therapy side effects were positively associated with depression in PLWHA in previous studies [33]. We found an increased risk of depression in PLWHA who were food insecure in studies that accounted for the effect of ART drugs [RR 1.96 (95\% CI 1.17-3.28)] as well as in studies that did not account for the effect of ART drugs [RR 2.43 (95\% CI 1.32-4.48)]. The heterogeneity between studies that adjusted for ART was not significant $\left(I^{2}=51.67 \% ; \mathrm{Q}=2.06 ; \mathrm{df}=1 ; \mathrm{p}=0.150\right)$ but it was significant in those studies that did not adjust ART drugs $\left(\mathrm{I}^{2}=88.93 \% ; \mathrm{Q}=36.14, \mathrm{df}=4, \mathrm{P}<0.001\right.$ ) (see Table 2).

\begin{tabular}{|c|c|c|c|c|c|c|c|c|c|c|}
\hline \multirow{2}{*}{$\frac{\text { Group by }}{\text { study design }}$} & \multirow[t]{2}{*}{ Study name } & \multicolumn{4}{|c|}{ Statistics for each study } & & \multicolumn{3}{|c|}{ Risk ratio and $95 \% \mathrm{Cl}$} & \multirow[b]{2}{*}{$\begin{array}{l}\text { Relative } \\
\text { weight }\end{array}$} \\
\hline & & $\begin{array}{l}\text { Risk } \\
\text { ratio }\end{array}$ & $\begin{array}{l}\text { Lower } \\
\text { limit }\end{array}$ & $\begin{array}{l}\text { Upper } \\
\text { limit }\end{array}$ & p-Value & & & \multirow{3}{*}{$10-$} & & \\
\hline Cohort & Palar 2018 & 4.190 & 2.788 & 6.296 & 0.000 & & & & & 21.07 \\
\hline Cohort & Kaplusky 2015 & 1.500 & 0.604 & 3.725 & 0.382 & & & & & 11.69 \\
\hline Cohort & Palar et al, 2015 & 1.640 & 1.261 & 2.132 & 0.000 & & & $\bullet$ & & 23.88 \\
\hline Cohort & Melissa 2014 & 2.710 & 1.507 & 4.872 & 0.001 & & & $\rightarrow$ & & 17.33 \\
\hline Cohort & Aibibula 2013 & 1.370 & 1.246 & 1.506 & 0.000 & & & - & & 26.03 \\
\hline Cohort & & 2.059 & 1.357 & 3.123 & 0.001 & & & 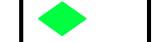 & & \\
\hline CS & Kinyanda 2011 & 2.890 & 1.398 & 5.973 & 0.004 & & & - & & 59.90 \\
\hline CS & Yeneabat 2012 & 3.830 & 1.577 & 9.302 & 0.003 & & & - & & 40.10 \\
\hline CS & & 3.235 & 1.845 & 5.675 & 0.000 & & & & & \\
\hline \multirow[t]{2}{*}{ Overall } & & 2.417 & 1.729 & 3.378 & 0.000 & & & & & \\
\hline & & & & & & 0.01 & 0.1 & 1 & 100 & \\
\hline
\end{tabular}

Table 2 Summary of the subgroup and Sensitivity analysis of all studies based on type of the severity food insecurity, adjustment for drug use, ART and social support and quality of the included studies

\begin{tabular}{|c|c|c|c|c|c|c|}
\hline \multirow[t]{2}{*}{ Subgroups } & \multirow[t]{2}{*}{ Studies, $\mathbf{n}$} & \multirow[t]{2}{*}{ Relative risk (\%) } & \multirow[t]{2}{*}{$95 \% \mathrm{Cl}$} & \multicolumn{2}{|c|}{$\begin{array}{l}\text { Heterogeneity } \\
\text { across the studies }\end{array}$} & \multirow{2}{*}{$\begin{array}{l}\text { Heterogeneity } \\
\text { between the groups ( } P \\
\text { value) }\end{array}$} \\
\hline & & & & $1^{2}$ & $P$ value & \\
\hline \multicolumn{6}{|c|}{ Level of food insecurity } & 0.813 \\
\hline Mild & 2 & 1.83 & $1.09-3.07$ & 75.28 & 0.044 & \\
\hline Moderate & 2 & 1.95 & $0.85-4.53$ & 81.34 & 0.021 & \\
\hline Severe & 2 & 2.59 & $1.03-6.48$ & 93.02 & $<0.001$ & \\
\hline \multicolumn{6}{|c|}{ Adjustment for drug use } & 0.134 \\
\hline Adjusted & 2 & 1.63 & $1.27-2.102$ & 0.00 & 0.850 & \\
\hline Not adjusted & 5 & 2.71 & $1.46-5.00$ & 89.83 & $<0.001$ & \\
\hline \multicolumn{6}{|c|}{ Adjustment for social support } & 0.902 \\
\hline Adjusted & 2 & 2.21 & $1.18-4.16$ & 18.02 & 0.269 & \\
\hline Not adjusted & 5 & 2.31 & $1.48-3.63$ & 89.07 & $<0.001$ & \\
\hline \multicolumn{6}{|c|}{ Adjustment for ART } & 0.599 \\
\hline Adjusted & 2 & 1.96 & $1.17-3.28$ & 51.67 & 0.269 & \\
\hline Not adjusted & 5 & 2.43 & $1.32-4.48$ & 88.93 & $<0.001$ & \\
\hline
\end{tabular}




\section{Funnel Plot of Standard Error by Log risk ratio}

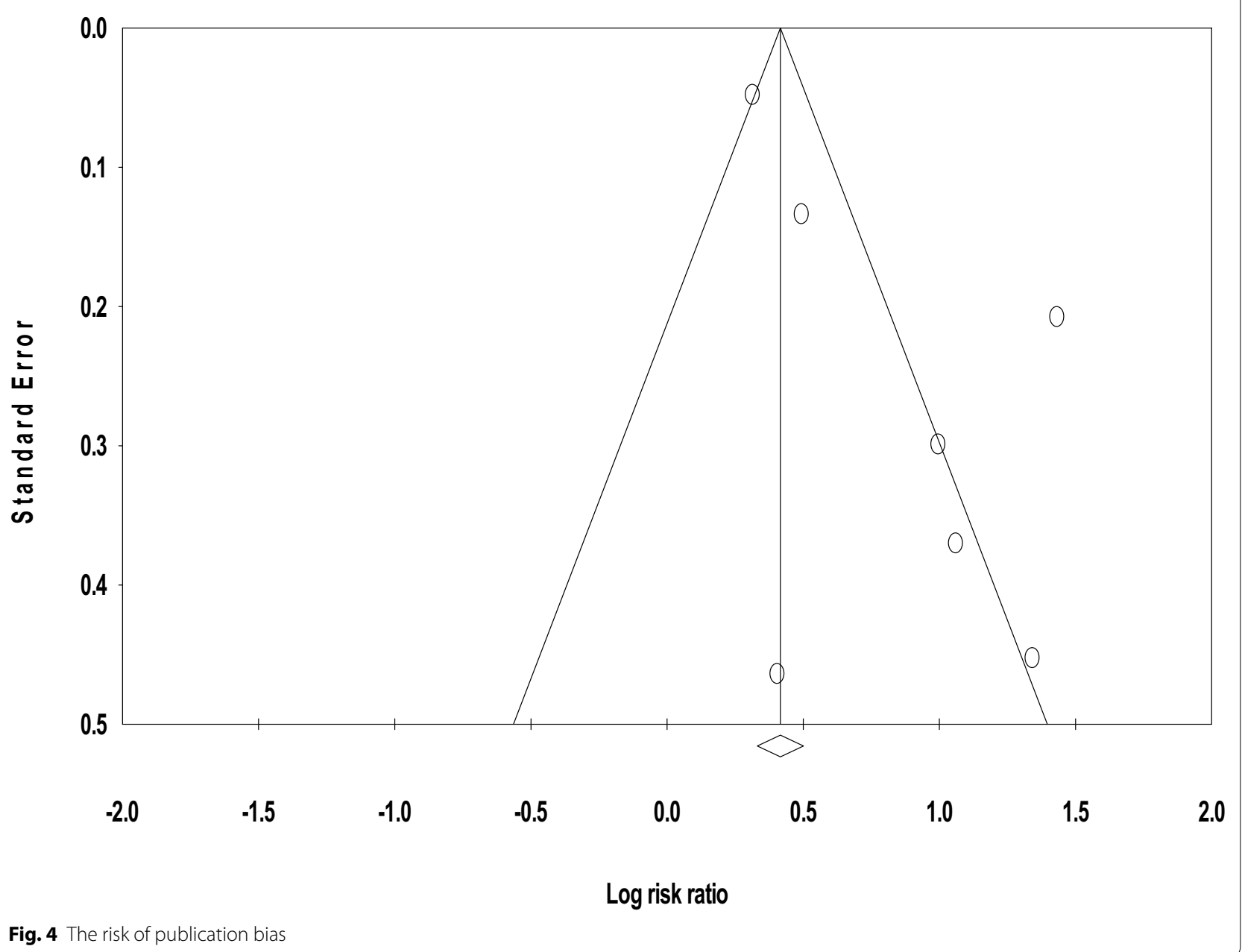

We also conducted a leave-one-out sensitivity analysis for further examining the possible cause of heterogeneity in the analysis of food insecurity and depression in PLWHA. This analysis resulted in a pooled estimated relative risk (RR) ranging between 1.88 (95\% CI 1.41-1.70) and 2.58 (95\% CI 2.52-4.29) after the deletion of a single study. This finding indicates that our findings were robust and not dependent on a single study (Additional file 2: Table S2).

\section{Discussion}

\section{Main findings}

This systematic review and meta-analysis assessed the risk of depression in PLWHA who were food insecure across five cohorts and two cross-sectional studies. Our final analysis demonstrated that there was a positive and significant association between food insecurity and greater risk of depression in PLWHA $(R R=2.28)$ that was unaffected by the level of adjustment for ART drug use, the degree of social support, as well as substance use (drug use). When we limit the analysis by the level of food insecurity, the risk was higher for severe food insecurity $(R R=2.59)$ followed by moderate $(R R=1.95)$ and mild food insecurity $(R=1.83)$, which supports the robustness of the main analysis. This finding suggests the necessity of the application of early screening and intervention strategies of food insecurity in PLWHA.

However, the included cross-sectional studies, the sample sizes, and the level of adjustment for the potential confounding factors must be considered. The level of adjustment factors was inconsistent in the included seven studies. Drug use (2 studies), age of participants (4 studies), on ART (2 studies), and social support (2 studies) were the most common potential confounders taken into account in the included studies. Only one study accounted for the possible confounding effects of the 
previous history of depression [27]. This study found a significant and week association for moderate food insecurity and moderate association for severe food insecurity, but the association was not significant for mild food insecurity. This result suggests the possibilities that the association seen in studies with a lower level of adjustment could be due to chance or the effects of confounding. Supporting this view, a substantial body of research showed a greater risk of depression in those PLWHA who substance users were, had a previous history of depression, as well as poor social support. Thus, in studies, which did not account for the effect of the above factors, the observed association between food insecurity and greater risk of depression could be due to the confounding effect of unmeasured drug use, ART drugs as well as lack of social support.

In fact, the robustness of an increased risk of depression in PLWHA with food insecurity was supported by our $\mathrm{s}$ analysis that we conduct in the current study: Firstly, the robustness of the observed association between food insecurity and depression was supported by our dose-response analysis. In this analysis, we found a greater risk of developing depression in those participants with severe food insecurity followed by moderate and mild food insecurity. These findings suggest the possible causal association between food insecurity and depression. Secondly, the robustness of the association observed in the current study was also supported by the sensitivity analyses that we conducted restricting the analysis to studies that controlled the confounding effects of drug use, ART drugs, and social support. In this analysis, we found the increased risk of depression in those PLWHA studies which accounted for the possible effects of drug use [RR 1.63 (95\% CI 1.27-2.10)] social support [RR 2.21 (95\% CI 1.18-4.16)] as well as those studies that adjusted for effects of ART drugs [RR 1.96 (95\% CI $1.17-3.28)]$.

\section{Differences among the studies included in the meta-analysis}

Even though our meta-analysis resulted in a significant association between food insecurity and depression in PLWHA, the observed differences across the seven studies led to a significant level of between-study heterogeneity in our final analysis. The stage of the disease, the country, and the exposed population differed on a number of characteristics which may have contributed to the variance in the risk of depression in those PLWHA who were food insecure. Nevertheless, our leave-oneout sensitivity analysis indicated that the risk of developing depression remained virtually unchanged from the main analysis. This finding suggests that our findings were strong and not significantly influenced by a single study. Additionally, our subgroup analysis and sensitivity analysis by the degree of food insecurity as well as the level of adjustment to a range of confounding factors supported the robustness of our findings. Moreover, in order to make the finding of the current meta-analysis meaningful, we have used a random-effects model to pool risk estimates from the individual studies. It is widely held that the summary effect estimates in the random effect model meta-analysis are more conservative than fixed effect summaries in the epidemiological meta-analysis, suggesting the robustness of our findings [20].

In our study, two of the evidence came from cross-sectional studies therefore the possibility that depression in PLWHA may lead to rather than precede the diagnosis of food insecurity might be considered. This is because epidemiologic evidence reported a reciprocal relationship between food insecurity and depressive symptoms [34]. Supporting our view, scientific studies have found that depressive symptoms were significantly associated with food insecurity [34-36]. In fact, this may not be a major concern in our study because when we limit our analysis to cohort studies where exposure (food insecurity) certainly precede the outcome (depression), we found a significant association between food insecurity and the increased risk of depression [RR 2.06 (95\% CI 1.36-3.12)].

\section{Possible mechanisms}

There is a range of explanations for the associations between food insecurity and increased risk of depression in PLWHA. Firstly, food insecurity is linked with incomplete HIV viral load suppression and less immune reconstitution in PLWHA, which in turn linked with a higher risk of depression [37-39]. Secondly, food insecurity is also associated with a significant reduction in CD4 count, which has been consistent, associated with a greater risk of depression in PLWHA in previous studies [40-42]. Thirdly, the rates of underweight are higher in food-insecure PLWHA as compared to food-secure people and underweight has been associated with a higher risk of depression in several epidemiologic studies [43, 44]. Furthermore, food insecurity is associated with a higher risk of opportunistic infections and other comorbid conditions, which are among the major risk factors of depression among PLWHA $[45,46]$. Finally, food insecurity is associated with reduced social capital, and higher levels of (or increased level of) social isolation, stigma, stress, and loneliness, which are in turn linked with increased risk of depression in those food-insecure people [47, 48].

\section{Strength and limitations}

This systematic review and meta-analysis have several strengths: Firstly. First, we utilized a predesigned search strategy, data abstraction, quality assessments, 
analysis, data extraction, and quality assessment to minimize the reviewer's bias. Secondly, we performed a sensitivity and subgroup analysis based on drug use, level of social support, and use of ART drugs to identify the small study effect and the risk of heterogeneity in analyses of the risk of depression and those with food insecurity. Thirdly, we use a standard tool to evaluate the quality of the included studies (NOS) and our evaluations showed that the methodologic qualities of the included studies were good.

However, the current review also has some limitations: (1) our meta-analysis resulted in significant associations between food insecurity and depression, but the degree of adjustments was inconsistent across the studies and important confounding variables including the effects of drug use, social support, previous history of depression, as well as ART drugs, were not adjusted in most studies. (2) Our final analysis showed significant heterogeneity between the studies. However, the observed variations between the studies may not be a major issue because our sensitivity and subgroup analysis resulted in a greater risk of depression in those food-insecure participants in both cohort 2.06 (95\% CI 1.36-3.12)) and cross-sectional 3.24 (95\% CI 1.85-5.68) studies. (3) The inclusion of a relatively low number of studies in our subgroup and sensitivity analysis is the other limitation of this review, which might reduce the precision of the reported estimate. (4) Pertinent studies published in a language other than English may have been missed. Finally, we found a significant publication bias the possibility of publication bias indicating the possibilities of remained studies due they may not be reported or published based on their findings or other factors. (5) We have not conducted the literature search in PsycINFO to identify studies relevant to the current review, which is one of the authoritative databases in mental health. In fact, we have conducted our systematic search for relevant studies in the three commonly used databases in mental health such as EMBASE, PubMed, and Scopus. We have also tried to include all the potential articles relevant to the review by our manual search and we believe that we have included the required important articles to estimate the pooled relative risk for the association between food insecurity and the risk of depression in people living with HIV/AIDS.

\section{Conclusion}

This systematic review and meta-analysis suggest food insecurity is associated with an increased risk of depression in PLWHA. Early screening for food insecurity and depression is warranted in PLWHA.

\section{Supplementary information}

Supplementary information accompanies this paper at https://doi. org/10.1186/s12981-020-00291-2.

Additional file 1: Table S1. The quality of the included studies based on NOS score (9 point score).

Additional file 2: Table S2. The sensitivity analysis of food insecurity and the risk of depression in PLWHA after each study removed.

\section{Abbreviations}

AIDS: Acquired Immune Deficiency Syndrome; BDI: Beck Depression Inventory; CES-D: Centre for Epidemiologic Studies Depression Scale-Revised; HFIAS: Household Food Insecurity Access Scale; HFSSM: Household Food Insecurity Survey Module; HIV: Human Immunodeficiency Virus; MINI: Mini-International Neuropsychiatric Interview; OR: Odds Ratio; PLWHA: People living with human immunodeficiency virus (HIV)/Acquired immune deficiency syndrome (AIDS); RR: Relative risk.

\section{Acknowledgements \\ We are very thankful to all the authors of the included articles.}

\section{Authors' contributions}

GA conceptualized the study, developed the methodology, conducted the analysis, and wrote the first draft of the manuscript. MS reviewed abstracts extracted the data and assessed the quality. LT reviewed data extraction and quality evaluation. All authors read and approved the final manuscript.

\section{Funding}

No external funding obtained for this systematic review and meta-analysis.

Availability of data materials

All data generated and analyzed during this study are included in this review.

Ethical approval and consent to participate

Not applicable.

Consent for publications

Not applicable.

Competing interest

The authors declare that they have no competing interests.

\section{Author details}

${ }^{1}$ Research and Training Department, Amanuel Mental Specialized Hospital Addis Ababa, PO BOX 1971, Addis Ababa, Ethiopia. ${ }^{2}$ School of Public Health, Curtin University, Perth, WA, Australia. ${ }^{3}$ College of Health Sciences, Axum University, Axum, Ethiopia.

Received: 16 July 2019 Accepted: 11 June 2020

Published online: 22 June 2020

\section{References}

1. US Department of Agriculture. Definitions of Food Security. 2019. https:// www.ers.usda.gov/topics/food-nutrition-assistance/food-security-in-theus/definitions-of-food-security.aspx

2. Heflin CM, Altman CE, Rodriguez LL. Food insecurity and disability in the United States. Disab Health J. 2019;12(2):220-6.

3. Tata Ngome PI, Shackleton C, Degrande A, Nossi EJ, Ngome F. Assessing household food insecurity experience in the context of deforestation in Cameroon. Food Policy. 2019;84:57-65.

4. Chakona G, Shackleton CM. Food insecurity in South Africa: to what extent can social grants and consumption of wild foods eradicate hunger? World Development Perspectives. 2019;13:87-94.

5. Coleman-Jensen A, Gregory C, Singh A. Household food security in the United States in 2013. USDA-ERS Economic Research Report Number 173. 2014. https://doi.org/10.2139/ssrn.2504067 
6. Chopra M, Daviaud E, Pattinson R, Fonn S, Lawn JE. Saving the lives of South Africa's mothers, babies, and children: can the health system deliver? Lancet. 2009;374(9692):835-46.

7. Whittle HJ, Palar K, Seligman HK, Napoles T, Frongillo EA, Weiser SD. How food insecurity contributes to poor HIV health outcomes: qualitative evidence from the San Francisco Bay Area. Soc Sci Med. 2016;170:228-36.

8. Weiser SD, Palar K, Hatcher AM, Young SL, Frongillo EA. Food insecurity and health: a conceptual framework. In: Ivers $L$ (ed) Food insecurity and public health. CRC Press; 2015. p. 23-50. https://www.crcpress.com/Food-Insec urity-and-Public-Health/lvers/p/book/9781466599055

9. Weiser SD, Frongillo EA, Ragland K, Hogg RS, Riley ED, Bangsberg DR. Food insecurity is associated with incomplete HIV RNA suppression among homeless and marginally housed HIV-infected individuals in San Francisco. J Gen Intern Med. 2009;24(1):14-20.

10. Idrisov B, Lunze K, Cheng DM, Blokhina E, Gnatienko N, Patts G, Bridden C, Chaisson C, Weiser SD, Krupitsky E, et al. Food insecurity and HIV progression among Russians with heavy alcohol consumption. Drug Alcohol Depend. 2017;171:e93.

11. Palar K, Frongillo EA, Escobar J, Sheira LA, Wilson TE, Adedimeji A, Merenstein D, Cohen MH, Wentz EL, Adimora AA, et al. Food Insecurity, Internalized Stigma, and Depressive Symptoms Among Women Living with HIV in the United States. AIDS Behav. 2018;22(12):3869-78.

12. Heylen E, Panicker ST, Chandy S, Steward WT, Ekstrand ML. Food insecurity and its relation to psychological well-being among south indian people living with HIV. AIDS Behav. 2015;19(8):1548-58.

13. Kinyanda E, Hoskins $\mathrm{S}$, Nakku J, Nawaz S, Patel V. Prevalence and risk factors of major depressive disorder in HIV/AIDS as seen in semi-urban Entebbe district, Uganda. BMC Psychiatry. 2011;11:205.

14. Kapulsky L, Tang AM, Forrester JE. Food insecurity, depression, and social support in HIV-infected Hispanic individuals. J Immigr Minor Health. 2015;17(2):408-13.

15. Moher D, Liberati A, Tetzlaff J, Altman DG, Group P. Preferred reporting items for systematic reviews and meta-analyses: the PRISMA statement. PLoS Med. 2009;6(7):e1000097.

16. Moher D, Shamseer L, Clarke M, Ghersi D, Liberati A, Petticrew M, Shekelle $P$, Group P-P. Preferred reporting items for systematic review and meta-analysis protocols (PRISMA-P) 2015 statement. Syst Rev. 2015;4(1):1

17. Stang A. Critical evaluation of the Newcastle-Ottawa scale for the assessment of the quality of nonrandomized studies in meta-analyses. Eur J Epidemiol. 2010;25(9):603-5.

18. Herzog R, Álvarez-Pasquin MJ, Díaz C, Del Barrio JL, Estrada JM, Gil Á. Are healthcare workers' intentions to vaccinate related to their knowledge, beliefs and attitudes? a systematic review. BMC Public Health. 2013;13(1):154.

19. Borenstein M, Hedges L, Higgins J, Rothstein H. Comprehensive metaanalysis version 2. Englewood: Biostat; 2005. p. 104.

20. Borenstein M, Hedges LV, Higgins J, Rothstein HR. A basic introduction to fixed-effect and random-effects models for meta-analysis. Res Synth Methods. 2010;1(2):97-111.

21. Higgins JP, Thompson SG, Deeks JJ, Altman DG. Measuring inconsistency in meta-analyses. Br Med J. 2003;327(7414):557.

22. Patsopoulos NA, Evangelou E, loannidis JP. Sensitivity of between-study heterogeneity in meta-analysis: proposed metrics and empirical evaluation. Int J Epidemiol. 2008;37(5):1148-57.

23. Egger M, Smith GD, Schneider M, Minder C. Bias in meta-analysis detected by a simple, graphical test. BMJ. 1997;315(7109):629-34.

24. Kinyanda E, Hoskins S, Nakku J, Nawaz S, Patel V. Prevalence and risk factors of major depressive disorder in HIV/AIDS as seen in semi-urban Entebbe district, Uganda. BMC Psychiatry. 2011;11(no pagination):205.

25. Davey-Rothwell MA, Flamm L, Kassa HT, Latkin CA. Food insecurity and depressive symptoms: comparison of drug using and nondrug-using women at risk for HIV. J Community Psychol. 2014;42(4):469-78.

26. Aibibula W, Cox J, Hamelin AM, Moodie EEM, Naimi Al, McLinden T, Klein $M B$, Brassard P. Impact of food insecurity on depressive symptoms among HIV-HCV co-infected people. AIDS Behav. 2017;21 (12):3464-72.

27. Palar K, Kushel M, Frongillo EA, Riley ED, Grede N, Bangsberg D, Weiser SD. Food insecurity is longitudinally associated with depressive symptoms among homeless and marginally-housed individuals living with HIV. AIDS Behav. 2015;19(8):1527-34.

28. Yeneabat T, Bedaso A, Amare T. Factors associated with depressive symptoms in people living with HIV attending antiretroviral clinic at Fitche Zonal Hospital, Central Ethiopia: cross-sectional study conducted in 2012. Neuropsychiatr Dis Treat. 2017;13:2125-31.

29. Carleton RN, Thibodeau MA, Teale MJN, Welch PG, Abrams MP, Robinson T, Asmundson GJG. The center for epidemiologic studies depression scale: a review with a theoretical and empirical examination of item content and factor structure. PLoS ONE. 2013;8(3):e58067.

30. Beck A, Steer R, Brown GJSA, TX: BDI-II, Beck depression inventory: manual: Psychological Corp. 1996.

31. Tuunainen A, Langer RD, Klauber MR, Kripke DF. Short version of the CES-D (Burnam screen) for depression in reference to the structured psychiatric interview. Psychiatry Res. 2001;103(2-3):261-70.

32. Pettersson A, Modin S, Wahlström R, af Winklerfelt Hammarberg S, Krakau I. The Mini-International Neuropsychiatric Interview is useful and well accepted as part of the clinical assessment for depression and anxiety in primary care: a mixed-methods study. BMC Fam Pract. 2018;19(19):1-13.

33. Liu H, Zhao M, Ren J, Qi X, Sun H, Qu L, Yan C, Zheng T, Wu Q, Cui Y. Identifying factors associated with depression among men living with HIV/AIDS and undergoing antiretroviral therapy: a cross-sectional study in Heilongjiang, China. Health Qual Life Outcomes. 2018;16(1):190.

34. Casey P, Goolsby S, Berkowitz C, Frank D, Cook J, Cutts D, Black MM, Zaldivar $\mathrm{N}$, Levenson S, Heeren TJP. Maternal depression, changing public assistance, food security, and child health status. Pediatrics. 2004;113(2):298-303.

35. Whitaker RC, Phillips SM, Orzol SMJP. Food insecurity and the risks of depression and anxiety in mothers and behavior problems in their preschool-aged children. Pediatrics. 2006;118(3):e859-68.

36. Huddleston-Casas C, Charnigo R. Simmons LAJPhn: Food insecurity and maternal depression in rural, low-income families: a longitudinal investigation. Public Health Nutr. 2009;12(8):1133-40.

37. Alexy E, Feldman M, Thomas J, Irvine M. Food insecurity and viral suppression in a cross-sectional study of people living with HIV accessing Ryan White food and nutrition services in New York City. The Lancet. 2013;382:S15

38. Aibibula W, Cox J, Hamelin AM, Moodie E, Naimi Al, McLinden T, Klein MB, Brassard P. Food insecurity may lead to incomplete HIV viral suppression and less immune reconstitution among HIV/hepatitis C virus-coinfected people. HIV Med. 2018;19(2):123-31.

39. Irwin MR, Archer G, Olmstead R, Brown TT, Teplin LA, Patel SR, Abraham AG, Breen EC. Increased risk of depression in non-depressed HIV infected men with sleep disturbance: prospective findings from the Multicenter AIDS Cohort Study. EBioMedicine. 2018;36:454-60.

40. Ayano G, Solomon M, Abraha M. A systematic review and meta-analysis of epidemiology of depression in people living with HIV in east Africa. BMC Psychiatry. 2018;18(1):254.

41. Amanor-Boadu S, Hipolito MS, Rai N, McLean CK, Flanagan K, Hamilton FT, Oji V, Lambert SF, Le HN, Kapetanovic S, et al. Poor CD4 count is a predictor of untreated depression in human immunodeficiency virus-positive AfricanAmericans. World J Psychiatry. 2016;6(1):128-35.

42. Kaharuza FM, Bunnell R, Moss S, Purcell DW, Bikaako-Kajura W, Wamai $\mathrm{N}$, Downing R, Solberg P, Coutinho A, Mermin JJA, et al. Depression and CD4 cell count among persons with HIV infection in Uganda. AIDS Behav. 2006;10(1):105-11.

43. de Wit LM, van Straten A, van Herten M, Penninx BWJH, Cuijpers P. Depression and body mass index, a u-shaped association. BMC Public Health. 2009:9:14.

44. Weiser S, Fernandes K, Brandson E, Lima V, Anema A, Bangsberg D, Hogg RJJAIDS. The impact of food insecurity and body mass index on mortality among HIV-infected individuals first initiating HAART. J Acquir Immune Defic Syndr. 2009;52:342-9.

45. Weiser SD, Tsai AC, Gupta R, Frongillo EA, Kawuma A, Senkungu J, Hunt PW, Emenyonu NI, Mattson JE, Martin JN, et al. Food insecurity is associated with morbidity and patterns of healthcare utilization among HIV-infected individuals in a resource-poor setting. AIDS. 2012;26(1):67-75.

46. Tesfaw G, Ayano G, Awoke T, Assefa D, Birhanu Z, Miheretie G, Abebe G. Prevalence and correlates of depression and anxiety among patients with 
HIV on-follow up at Alert Hospital, Addis Ababa, Ethiopia. BMC Psychiatry. 2016;16(1):368.

47. Burris M, Kihlstrom L, Arce KS, Prendergast K, Dobbins J, McGrath E, Renda A, Shannon E, Cordier T, Song Y, et al. Food insecurity, loneliness, and social support among older adults. J Hunger Environ Nutr. 2019. https://doi. org/10.1080/19320248.2019.1595253.

48. Martin MS, Maddocks E, Chen Y, Gilman SE, Colman I. Food insecurity and mental illness: disproportionate impacts in the context of perceived stress and social isolation. Public health. 2016;132:86-91.

\section{Publisher's Note}

Springer Nature remains neutral with regard to jurisdictional claims in published maps and institutional affiliations.
Ready to submit your research? Choose BMC and benefit from:

- fast, convenient online submission

- thorough peer review by experienced researchers in your field

- rapid publication on acceptance

- support for research data, including large and complex data types

- gold Open Access which fosters wider collaboration and increased citations

- maximum visibility for your research: over 100M website views per year

At BMC, research is always in progress.

Learn more biomedcentral.com/submissions 